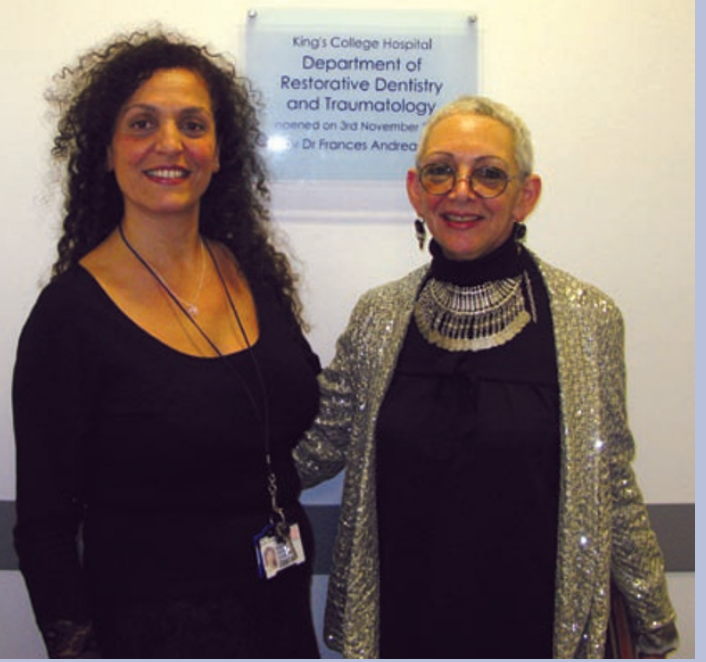

Serpil Djemal (left) with

Dr Frances Andreasen

\title{
TRAUMATIC TOOTH INJURY CLINIC OPENED
}

A brand new, state-of-the-art restorative dentistry and traumatology clinic was unveiled at King's College NHS Foundation Trust, on 3 November 2010. It is the first clinic in the UK dedicated to the management of adults who have sustained traumatic injuries to their teeth.

The clinic, in Denmark Hill, south-east London, was opened by world-renowned dental traumatologist Dr Frances Andreasen at a celebration attended by 100 staff, students and patients.

The multi-purpose clinic will provide the highest possible quality of care for adult dental trauma patients and complements the existing trauma clinic in the Department of Paediatric Dentistry.
Acute and follow-up care will be provided by the Lead, Miss Serpil Djemal, Consultant in Restorative Dentistry, and multidisciplinary care will be provided in collaboration with oral and maxillofacial surgery, oral surgery, orthodontics and postgraduate endodontics students from King's College London University.

Dr Andreasen said she was 'delighted to be associated with such a much needed and visionary clinic in managing adult dental trauma patients'.

Miss Djemal said, 'We hope to receive referrals from primary care, secondary care and tertiary care in addition to “walk in" patients with acute injuries.'

\section{TEETH HAVE IMPROVED SINCE THE 1970s}

The British Dental Association (BDA) has given a positive reception to the preliminary findings from the 2009 Adult Dental Health Survey (ADHS).

The report shows that adults are retaining at least some of their natural teeth later into life. Additionally, the report found that $86 \%$ of adults had 21 or more natural teeth. In 1978, this was the case for only $74 \%$ of adults.

'Fluoride toothpaste, greater awareness of the importance of a healthy diet and regular visits to the dentist have all undoubtedly contributed to the better dental health we see in adults today,' said Professor Damien Walmsley, the BDA's Scientific Adviser.

The report also confirms the relationship between low socio-economic status and poorer oral health. Ninety-one percent of people from managerial and professional households have 21 or more natural teeth compared to $85 \%$ from intermediate occupation households and 79\% from routine and manual occupation households.

'Addressing this [link] must be a priority for the UK's governments,' added Professor Walmsley.

The survey also found that 12\% of adults who have ever been to the dentist have extreme dental anxiety about the situation.

\section{OUSTANDING DENTAL PROFESSIONALS HONOURED}

More than 25 dentists and dental care professionals (DCPs) received awards at the fifth British Dental Association (BDA) Honours and Awards Dinner, held on 24 November at Hotel Russell in London.

The dental team from the River Practice Specialist Centre in Truro, Cornwall, were presented with the 2010 BDA Good Practice Scheme Practice of the Year Award (pictured). BDA Fellowship, which is the highest honour the BDA bestows, was awarded to Ross Hobson and Mavis Phipps for outstanding and distinguished service to the BDA and the dental profession.

The John Tomes Medal, which is awarded by the BDA in recognition of scientific eminence and outstanding service to the dental profession, was presented to Professors John McCabe and David Wray.
BDA Life Membership was awarded to Alex Matthewson, John Rostron MBE and John Williams CBE. The BDA Distinguished Member award was given posthumously to Trevor Payne and was collected by his widow, Judy. It recognises Trevor's long, exceptional and valuable service to the BDA and acknowledges commitment to the operation and welfare of the Association.

Five new names were entered on the BDA Roll of Distinction: John Attenborough, Simon Gambold, Richard Hayward, Gillian Weir and Liana Zoitopoulos. The awards to John and Liana were made posthumously.

'These awards underline the hard work that individuals and teams carry out to improve knowledge and patient care and further the cause of dentistry,' said Peter Ward, BDA Chief Executive.

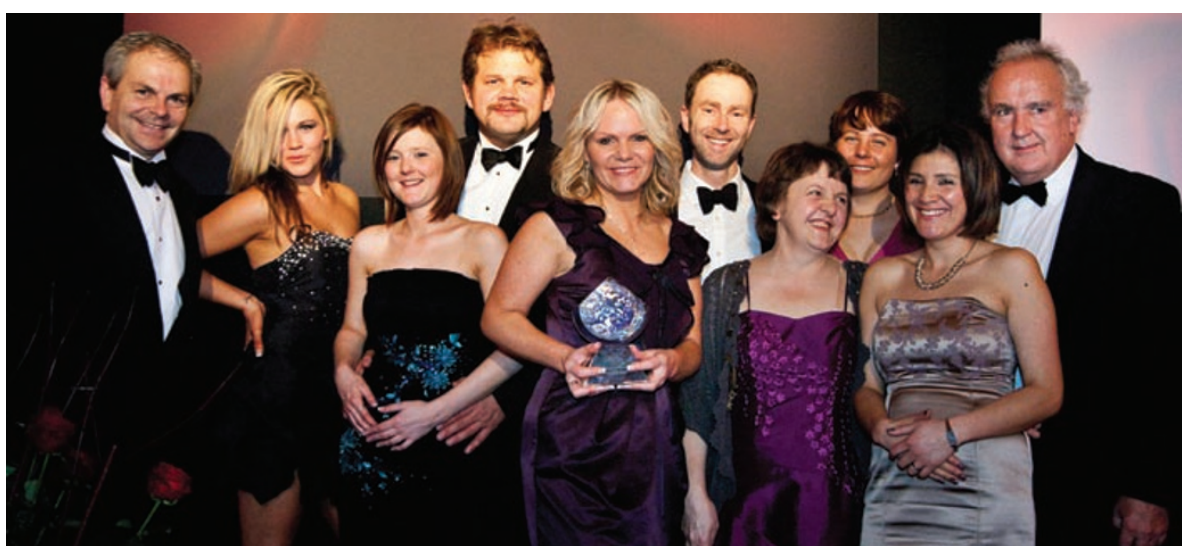

